\title{
Correlation of Male Genital Filaments and Female Spermathecal Ducts in New World Sand Flies of the Lutzomyia intermedia Species Complex (Diptera: Psychodidae, Phlebotominae)
}

\author{
Carlos Brisola Marcondes $/{ }^{+}$, Bruce Alexander* \\ Departamento de Microbiologia e Parasitologia, Centro de Ciências Biológicas, Universidade Federal de Santa Catarina, \\ 88040-900 Florianópolis, SC, Brasil *Centro de Pesquisas René Rachou-Fiocruz, Belo Horizonte, MG, Brasil
}

The lengths of the male genital filaments and female spermathecal ducts were measured in phlebotomine sand flies of the Lutzomyia intermedia species complex and the ratios between these characters calculated. Ratios for L. intermedia s. s. from Northeast vs Southeast Brazil (Espirito Santo and Minas Gerais), Espirito Santo/Minas Gerais vs Rio de Janeiro/São Paulo and L. intermedia vs L. neivai were significantly different at $P<0.1,0.05$ and 0.01 respectively when compared using ANOVA. The spermathecal ducts and genital filaments of L. intermedia were significantly longer than those of $\mathrm{L}$. neivai $(P<0.01)$ and could be used to differentiate these species. The taxonomic and biological significance of these differences is discussed.

Key words: Lutzomyia intermedia - Phlebotominae - Lutzomyia neivai - morphometry - reproduction

Phlebotomine sand flies, particularly those of the New World genus Lutzomyia, exhibit considerable morphological variation with respect to the genitalia of both sexes. Unlike most Diptera, including the other members of the family Psychodidae, the organs of sperm transfer in phlebotomines present a bipartite condition (Downes 1968). The principal morphological characteristics used to distinguish between species are the external genitalia of the male, consisting of paired structures that grip the female during copula, and the internal genitalia of the female, consisting of a common duct branching to paired individual ducts terminating in spermathecae. The testes of the males are connected to a genital pump, which connects via the aedeagus to a pair of "genital filaments" (actually ducts). These filaments are the structures that penetrate the body of the female and deposit the spermatozoa, rather than the aedeagus as in most insects.

Hertig (1949) was able to anaesthetise, clear and slide mount a copulating pair of Phlebotomus perfiliewi Parrot, showing the genital filaments of the male entering the genital ducts of the female, with their extremities almost reaching the spermathecae. The relationship between male genital filaments and spermathecal ducts has been studied in few other sand fly species. Forattini (1973) reviewed previous studies on copula in phlebotomine sand flies and illustrated two insects in copula of a species he referred to as "Psychodopygus intermedius"; these were later identified as L. neivai (Pinto) (Marcondes 1997). Ilango and Lane (2000) observed considerable variation among

${ }^{+}$Corresponding author. Fax: $+55-48-331.9258$. E-mail: cbrisola@mbox1.ufsc.br

Received 13 December 2002

Accepted 18 June 2003
26 Old World species with respect to the ratio between the lengths of the male genital filaments and female spermathecal ducts. The ratio between the length of male genital filaments and that of spermathecal ducts of their co-specific females may be important to the lock-and-key mechanism of the beetle Bambra invisibilis (Dybas \& Dybas 1981).

In view of the relative lack of information on this topic in New World species, the morphology of members of the Lutzomyia intermedia species complex was studied. This taxon includes $L$. intermedia (Lutz \& Neiva) and L. neivai (Pinto), the latter resurrected by Marcondes (1996). The females can be easily differentiated by the spermathecae and by the lengths of the spermathecal ducts, besides the number of cibarial horizontal teeth. Some proportions between genital and extra-genital structures (Marcondes \& Borges 2000) can differentiate males.

The two species have rather similar ecological requirements, occurring in habitats modified by human activities as well as some preserved forest areas (Gomes \& Galati 1989). However L. neivai occurs in colder, drier regions of Brazil than L. intermedia (Marcondes et al. 1998e) as well as Argentina, Paraguay and Bolivia (Marcondes et al. 1998b, e). In the Brazilian state of São Paulo, L. intermedia occurs between the eastern chain of mountains ("Serra do Mar") and the coast, while L. neivai has a more westerly distribution. The two species are sympatric at Pariqüera Açu (Marcondes 1996, 1998e).

Although neither species meets all the requirements of a vector cited by Killick-Kendrick (1990) both $L$. intermedia and $L$. neivai have been incriminated as vectors of Leishmania.

The genital ducts or filaments of 454 specimens (125 females and 329 males) of the L. intermedia species complex from Brazil, Argentina, Paraguay and Bolivia were measured during the present study, using an Olympus 
OSM- 221939 ocular. Insects were mounted using Canada balsam or NC (Nelson Cerqueira, Enecê in Portuguese), correcting the dimensions of the genital filaments according to Marcondes et al. (1998a). The insects were distributed among five groups, according to the species and region. The ratios between the means of the sum of the lengths of common and individual spermathecal ducts of females and the lengths of the genital filaments of males from the same region were obtained. Insects from localities at two distinct elevations in the state of Espírito Santo were also compared. Dimensions and ratios of the different regions were compared, analysing results by ANOVA, using Excel software.

Mean lengths of spermathecal ducts and genital filaments (+1SD) of specimens of $L$. intermedia s.s. from three areas of Brazil (Northeast, Espírito Santo/Minas Gerais and Rio de Janeiro/São Paulo) and three other countries (Argentina, Paraguay, and Bolivia) are shown in the Table.

The differences between the two species with respect to the lengths of the structures and genital filament/ spermathecal duct ratios were highly significant, as were some intraspecific differences between the ratios in $L$. intermedia from different regions. No significant differences were found either in the genital structures or in the ratios in the insects from the localities at different elevations; this agrees with the observations of Marcondes et al. (1999), who did not test the sum of the spermathecal ducts and the filament/duct ratio. Since in the present study insects from several localities were measured for each group, it would be useful to compare ratios from well-defined localities. The proportion between these lengths could therefore be used as a character to differentiate between these species (Marcondes 1996, Marcondes et al. 1998b, c, d, Marcondes \& Borges 2000). Geographical variation with respect to this ratio should also be studied. Ilango and Lane (2000) noted that the common spermathecal duct of $P$. argentipes is very large and the male aedeagus correspondingly wide. Since females of $L$. intermedia have long and relatively large common ducts and those of L. neivai very short ones, it would be interesting to study the shape and dimensions of the male aedeagi and their relationship with the common ducts. The results of the present study demonstrate that the genital filaments are longer than the spermathecal ducts, as found for 25 of the 26 taxa examined by Ilango and Lane (2000). This greater length of genital filaments would allow sperm displacement by males (Ilango, 1995 apud Ilango \& Lane 2000). These observations contradict the conclusion that lengths of genital filaments and those of spermathecal ducts are similar in sand flies, as proposed by Williams (1988).

Large numbers of species may occur together within a relatively small area, such as the 35 recorded at a single collecting site in Panama by Chaniotis et al. (1972). There would be a considerable risk of interspecific couplings in a situation of this type if the insects did not have some method of recognising members of the same species. Although sex pheromones have been described for a few species (Hamilton et al. 1999) such isolating mechanisms are unknown for most sand flies. Nevertheless it is unlikely that the morphological diversity of the genitalia in Lutzomyia spp. simply acts as a physical barrier to hybridisation.

Eberhard (1985) discussed the reasons why male copulatory structures in many groups of animals exhibit such variation in morphology. Two explications have been proposed, i.e., the "lock and key" and pleiotropy hypotheses. With respect to the first hypothesis, there are many groups of animals in which the complex genitalia of the females is unable to exclude the genitalia of males of other species. In pleiotropy, physical characteristics are effects of genes that code primarily for other characteristics, resulting in adaptations to the environment. This idea, however, does not explain why these incidental effects occur principally in genitalia rather than in other organs. According to Eberhard (1985), two mechanisms proposed could be involved: competition among males and selection by females. In approximately $30 \%$ of the species of insects studied, the males carry out

TABLE

Lengths of female spermathecal ducts and male genital filaments of phlebotomine sand flies of the Lutzomyia intermedia species complex from Brazil, Argentina, Paraguay, and Bolivia

\begin{tabular}{|c|c|c|c|c|c|c|c|c|c|}
\hline & \multicolumn{3}{|c|}{ Spermathecal ducts } & \multicolumn{3}{|c|}{ Genital filaments } & \multicolumn{3}{|c|}{ Genital filaments/ducts } \\
\hline & Mean & $\mathrm{N}$ & S.D. & Mean & $\mathrm{N}$ & S.D. & Mean & $\mathrm{N}$ & S.D. \\
\hline \multicolumn{10}{|c|}{ Lutzomyia intermedia } \\
\hline NE Brazil & $134^{\mathrm{A}}$ & 2 & 21.13 & $286.9^{\mathrm{A}}$ & 11 & 21.52 & $2.14^{\mathrm{A}}$ & 11 & 0.161 \\
\hline $\mathrm{ES} / \mathrm{MG}$ & $129.5^{\mathrm{A}}$ & 53 & 14.22 & $305.8^{\mathrm{A}}$ & 83 & 15.38 & $2.36^{\mathrm{B}}$ & 83 & 0.116 \\
\hline $\mathrm{RJ} / \mathrm{SP}$ & $123.7^{\mathrm{A}}$ & 23 & 16.12 & $304.2^{\mathrm{A}}$ & 103 & 22.82 & $2.71^{\mathrm{C}}$ & 103 & 0.207 \\
\hline Pooled results & $127.9^{\mathrm{E}}$ & 78 & 14.99 & $303.4^{\mathrm{E}}$ & 197 & 21.31 & $2.553^{\mathrm{E}}$ & 197 & 0.258 \\
\hline \multicolumn{10}{|l|}{ Lutzomyia neivai } \\
\hline SE Brazil & 108.5 & 20 & 7.34 & 294.5 & 103 & 22.18 & 2.71 & 103 & 0.204 \\
\hline Other countries & 108.6 & 27 & 11.07 & 291.2 & 29 & 21.2 & 2.68 & 29 & 0.195 \\
\hline Pooled results & $108.5^{\mathrm{F}}$ & 47 & 9.46 & $293.8^{\mathrm{F}}$ & 132 & 21.94 & $2.707^{\mathrm{F}}$ & 132 & 0.202 \\
\hline
\end{tabular}

NE: Northeast; RJ: state of Rio de Janeiro; MG: state of Minas Gerais; SP: state of São Paulo; SE: Southeast other countries: Argentina, Bolivia, and Paraguay; N: number examined; S.D.: standard deviation. Levels of significance of ANOVA: genital filaments/ ducts (A vs B, B vs C, A vs C) and L. intermedia vs L. neivai - all measurements (E vs F) - 0.01\%. 
some type of behaviour apparently designed to stimulate the female. In phlebotomines these could include vibration of the wings during copula and mechanical stimulation of the female abdomen by tufts and other structures on the copulatory apparatus of the males, as seen in some butterflies (Lorkovic 1952).

Large congregations of male sand flies at the bases of trees and other so-called diurnal resting sites probably represent courtship "leks" (Memmott 1991) where the males wait for the females to descend from the canopy to lay their eggs in the soil or leaf litter. Fertilisation of the eggs occurs shortly before oviposition and it would thus benefit a male sand fly to be the last to mate with a female. The females of many species of insects mate a second time before the sperm from the first insemination is exhausted. When this occurs, the spermatozoa of the second male preferentially fertilise the remaining eggs (Gwynne 1984). In damselflies, males remove the sperm of previous matings, the tip of the aedeagus being modified for this purpose (Waage 1984). In some species of phlebotomines, (including many members of the subgenus Nyssomyia Barrettto, to which both L. intermedia and L. neivai belong, the tips of the genital filaments also resemble spoons or hooks, their function being unknown. It would be interesting to determine whether these are also involved in sperm replacement.

\section{REFERENCES}

Chaniotis BN, Tesh RB, Correa MA, Johnson KM 1972. Diurnal resting sites of phlebotomine sandflies in a Panamanian tropical forest. J Med Entomol 9: 91-98.

Downes JA 1968. Notes on the organs and processes of sperm transfer in the lower Diptera. Can Entomol 100: 608-617.

Dybas LK, Dybas HS 1981. Coadaptation and taxonomic differentiation of sperm and spermathecae in featherwing beetles. Evolution 35: 168-174.

Eberhard WG 1985. Sexual Selection and Animal Genitalia, Harvard University Press, London, 244 pp.

Forattini OP 1973. Entomologia Médica, $4^{\circ}$ vol., Psychodidae; Phlebotominae; Leishmanioses; Bartoneloses, Edgar Blucher/EDUSP, São Paulo, 658 pp.

Gomes AC, Galati EAB 1989. Aspectos ecológicos da leishmaniose tegumentar americana. 7- Capacidade vetorial flebotomínea em ambiente florestal primário do sistema da Serra do Mar, região do Vale do Ribeira, Estado de São Paulo, Brasil. Rev Saúde Públ 23: 136-142.

Gwynne DT 1984. Male mating effort, confidence of paternity and insect sperm competition. In RL Smith, Sperm Competition and the Evolution of Animal Mating Systems, Academic Press, New York, p. 117-150.

Hamilton JGC, Brazil RP, Morgan RD, Alexander B 1999. Chemical analysis of oxygenated homosesquiterpenes: a putative sex pheromone from Lutzomyia lichyi (Diptera: Psychodidae). Bull Entomol Res 89: 139-145.

Hertig M 1949. The genital filaments of Phlebotomus during copulation. Proc Entomol Soc Washington 51: 265-268.
Ilango K, Lane RP 2000 Coadaptation of male aedeagal filaments and female spermathecal ducts of the Old World phlebotomine sand flies (Diptera: Psychodidae). J Med Entomol 37: 653-659.

Killick-Kendrick R 1990. Phlebotomine vectors of the leishmaniasis: a review. Med Vet Entomol 4: 1-24.

Lorkovic A 1952. L'accouplement artificiel chez les lépidopteres et son application dans les recherches sur la fonction de l'appareil génital des insectes. Physiol Comp Oecol 3: 313-319.

Marcondes CB 1996. A redescription of Lutzomyia (Nyssomyia) intermedia (Lutz \& Neiva, 1912), and resurrection of $L$. neivai (Pinto, 1926) (Diptera, Psychodidae, Phlebotominae). Mem Inst Oswaldo Cruz 91: 457-462.

Marcondes CB 1997. Morfometria e DNA Mitocondrial de Populações Sul Americanas de Lutzomyia (Nyssomyia) intermedia (Lutz \& Neiva, 1912) (Diptera, Psychodidae, Phlebotominae), $\mathrm{PhD}$ Thesis, Universidade Federal do Paraná, Curitiba, 260 pp.

Marcondes CB, Borges PSS 2000. Distinction of males of Lutzomyia intermedia (Lutz \& Neiva, 1912) complex by ratios between dimensions and by an artificial neural network (Diptera, Psychodidae, Phlebotominae). Mem Inst Oswaldo Cruz 95: 685-688.

Marcondes CB, Falqueto A, Lozovei AL 1998a. Influence of preparation methods on the dimensions of Lutzomyia intermedia (Lutz \& Neiva, 1912) (Diptera, Psychodidae, Phlebotominae). Mem Inst Oswaldo Cruz 93: 201-202.

Marcondes CB, Le Pont F, Lozovei AL 1998b Lutzomyia neivai (Pinto, 1926) in Bolivia (Diptera, Psychodidae, Phlebotominae). Mem Inst Oswaldo Cruz 93: 203-204.

Marcondes CB, Lozovei AL, Falqueto A, Brazil RP, Galati EAB, Aguiar GM, Souza NA 1999. Influence of altitude and latitude (Bergmann's rule) in dimensions of Lutzomyia intermedia (Lutz \& Neiva, 1912). Mem Inst Oswaldo Cruz 94: 693-700.

Marcondes CB, Lozovei AL, Galati EAB, Taniguchi HH 1998c. The usefulness of Bergmann's rule to the distinction of members of Lutzomyia intermedia species complex (Diptera, Psychodidae, Phlebotominae). Mem Inst Oswaldo Cruz 93: 363-364.

Marcondes CB, Lozovei AL, Galati EAB 1998d. Variações regionais e inter-específicas adicionais na morfologia de insetos do complexo Lutzomyia intermedia (Lutz \& Neiva, 1912) (Diptera, Psychodidae, Phlebotominae). Rev Saúde Públ 32: 519-525.

Marcondes CB, Lozovei AL, Vilela JH 1998e. Distribuição geográfica de flebotomíneos do complexo Lutzomyia intermedia (Lutz \& Neiva, 1912). Rev Soc Bras Med Trop 31: 51-58.

Memmott J 1991. Sand fly distribution and abundance in a tropical rain forest. Med Veter Entomol 5: 403-411.

Waage JK 1984. Sperm competition and the evolution of Odonate mating systems. In RL Smith, Sperm Competition and the Evolution of Animal Mating Systems, Academic Press, New York, p. 251-290

Williams P 1988. A female sand fly (Diptera: PsychodidaePhlebotominae) similar to Brumptomyia spinosipes (Floch \& Abonnenc, 1943). Mem Inst Oswaldo Cruz 83: 343-346. 